Opinion Section

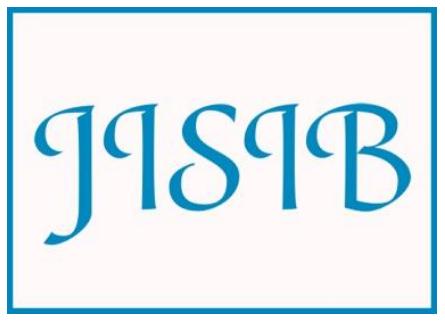

Available for free online at https://ojs.hh.se/

Journal of Intelligence Studies in Business Vol 4, No 1 (2014) 16-25

\title{
Analysis of knowledge transference processes in first mission activities of universities: portfolios as proposal of analytical tool for competitive intelligence functions
}

\author{
Victor Cavaller ${ }^{1}$ \\ ${ }^{1}$ Open University of Catalonia (UOC), Spain \\ Email: vcavaller@uoc.edu
}

Received December 11 2013, accepted April 7, 2014

\begin{abstract}
The relationship between higher education activities follows a sequential cycle focused on knowledge transference. The aim of this paper is to examine the details of the following associated questions of debate about KT (knowledge translation) in education mission activities (first mission): relationship between teaching activities and scientific research, correlation between learning and teaching quality, entrepreneurship and the Bologna Process: the reform of education systems and finally, learning \& teaching outcomes. This analysis allows a systematic approach to the specific goals of the Bologna Process that include promoting the student centred model, increasing the autonomy and accountability of universities, strengthening the responsibility of institutions for the quality of teaching, highlighting the excellence of learning, enhancing the quality of research and the transference of knowledge, as a basis for a competitive economy. In order to achieve this goal, from a $\mathrm{Cl}$ (competitive intelligence) perspective, portfolios represent a critical tool for education systems as training-for-self-assessment, promoting new forms of support for the excellence of learning \& teaching activities and designing of curricula and programmes.
\end{abstract}

KEYWORDS: Knowledge transference, university assessment, portfolios, competitive intelligence, Bologna process. 


\section{Opinion Section}

\section{Introduction}

In the last decades, the relationship between learning and teaching, traditionally defined as 'transmission of knowledge' activities, and the interconnection with research, understood as the 'generation of new knowledge' have become problematic (Elton 1992; Rowland 1996, Coaldrake and Stedman (1999). We could highlight the following reasons:

- "Knowledge is now generated in the context of application". (Nowotny et al. 2001) Gibbons explain the changes in the constitution of science and in research practice as a consequence of a new paradigm of knowledge production attributing to the growing contextualization and socialization of knowledge. (Gibbons et al., 1994) "The old paradigm of scientific discovery characterized by the hegemony of theoretical or, at any rate, experimental science; by an internally-driven taxonomy of disciplines; and by the autonomy of scientists and their host institutions, the universities - was being superseded by a new paradigm of knowledge production, which was socially distributed, application-oriented, trans-disciplinary, and subject to multiple accountabilities" (Nowotny et al. 2003).

- The 'learning and teaching' interaction has changed through a new model defined as student centred. "Students are not passive. They come with their own perceptual frameworks" (Erikson, 1984), "students learn in different ways" (Briggs-Myers, 1980; Kolb,1984), "learning is an active dynamic process" (Cross,1991), "students construct their own meaning by talking, listening, writing, reading, and reflecting on content, ideas, issues and concerns" (Meyers and Jones, 1993).

- The flow of KT processes involved draws a complex network relationship, and this factor has important repercussions in the domain of the first mission in higher education:

- First, the activities associated with the first mission of universities have two faces: teaching and learning. Learning processes, as a result of teaching processes, refers to the acquisition of knowledge, skills, and competencies. Teaching provides sources to learning, and learning provides professionals, researchers and also future teachers. We must appreciate this difference in order to set different actors, achievements and consequently, indicator systems, as a first criterion of classification, maintaining the loop of their relationship.

- Since now, we have seen that second mission activities are based on processes where scientific research provides new knowledge. We have showed activities that correspond to a first moment of diffusion and extension by means of scientific production and networks, and activities in a second moment when this shared scientific production crystallize in a knowledge product to commercialize or in a degree of expertise, as a guarantee for research contracts. It is important to distinguish the correlation of each of these two phases of research with teaching.

- Finally, the intangible benefits of higher education, the complexity and interdisciplinary are issues surrounding assessment and accountability in higher education. "Quality in higher education is a multidimensional concept, which should embrace all its functions, and activities: teaching and academic programmes, research and scholarship, staffing, students, buildings, facilities, equipment, services to the community and the academic environment". (Unesco, 1998) The lack of a definition of KT flow and parameters for this new paradigm that follows here the sequence of learningteaching-research activities - has been an obstacle to define indicators, and consequently, educational systems were witnessing a deep transformation currently ongoing to third mission requirements all around the world.

Furthermore, recently Chalmers (2007) has proposed a framework for dimensions of quality learning-teaching practice. The four dimensions are conceptualised in a "diagram with input, process, output and outcome indicators, all of which are necessary for a more complete understanding of the institution. The different levels of involvement of the institution and the people in the institution are identified as critical, as it is the people who must provide the commitment and the engagement with the process if change is to take place". (Chalmers, 2007). 


\section{Opinion Section}

For us, the relationship between higher education activities follows a sequential cycle in both directions, using the research mission as a link from learning-teaching to entrepreneurship, entrepreneurship as a link from research to learning-teaching, and learning-teaching as a link from entrepreneurship to research.

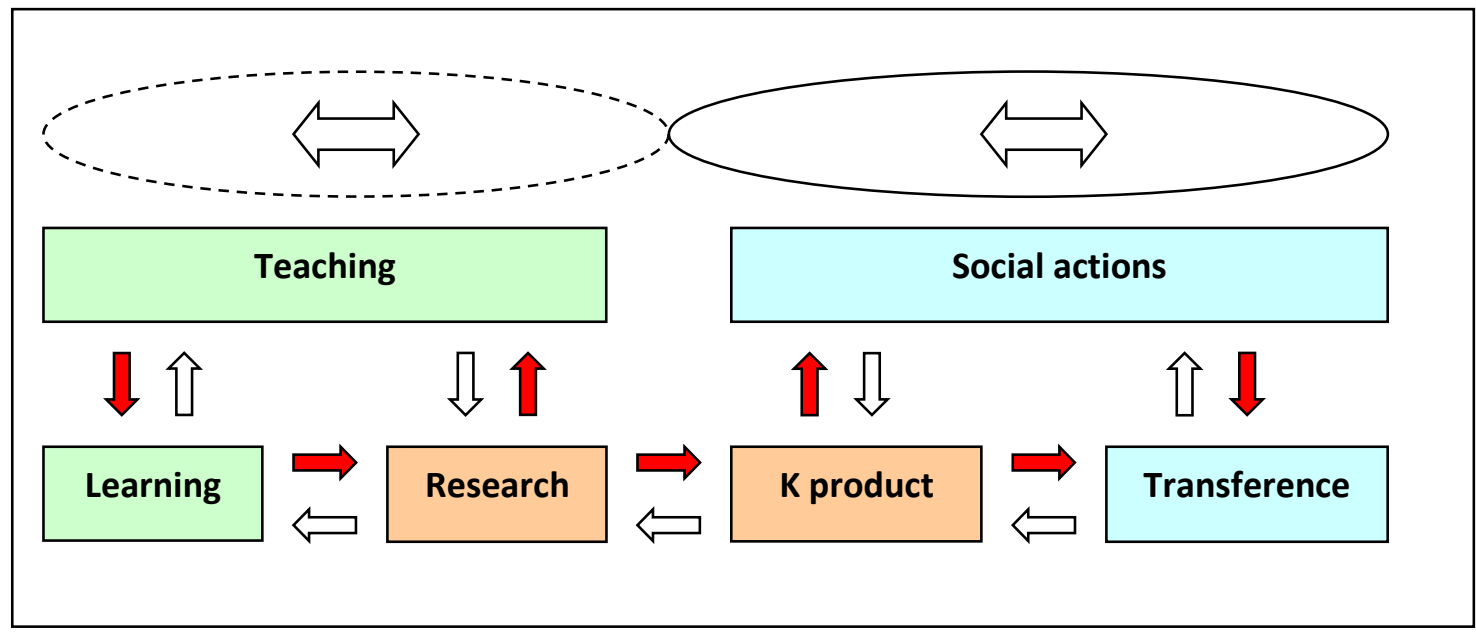

Figure 1: Stream activity of KT processes associated to three missions of universities

In the next sections, we will examine the details of the following associated questions of debate about $\mathrm{KT}$ processes in 1 st mission activities:

- Relationship between teaching activities and scientific research

- Correlation between learning and teaching quality

- Entrepreneurship and Bologna Process: the reform of education systems

- $\quad$ Learning \& Teaching outcomes: portfolios

\subsection{Relationship between learning, teaching and research activities}

There is considerable research literature that reviews empirical evidence on the complex interaction between learning $(\mathrm{L})$, teaching $(\mathrm{T})$ and their interconnection with research $(\mathrm{R})$ in higher education. The concept of "teaching-research nexus" has been explored by Trowler and Wareham (2007)

Making a review of the empirical evidence, we could explore their relationship, in descendant order (R-T-L: Research to Teaching to Learning) and in ascendant order (L-T-R: Learning to Teaching to Research), comparing the possible contrasting perspectives: Positive, Negative, and Null (adapting Qamar, 2004) on continuous or disrupted university scenarios where this sequence is developed.
In descendant order (R-T-L), a positive perspective would make evident that "research helps in expert and contemporary knowledge; leads to credibility enhancement, increase lecturer confidence and students appreciate teachers who present research". In ascendant order (L-T-R), a positive perspective would show that excellence in learning will become excellent future teaching and in a next step "teaching can be particularly good for young researchers because it can reinforce their ability to expound and clarify their thinking (...) and can elucidate gaps in the academic's knowledge base". The horizon in this order is entrepreneurship. Research is "thought to be good for staff development, institutional image and reputation, and student recruitment"

In both senses, a negative perspective would say: "There is limited time, energy, and commitment, for a faculty to do both teaching and research. Research and teaching are different enterprises, and require contrary personality characteristics". Dispersion of activities decreases quality.

From a null perspective, research and teaching are different enterprises, and there would not be a correlation between them, while in teaching and learning quality could observe only a weak relationship. Quality in research, teaching and learning would not be contradictory goals, but there would not be perceptible evidence in any of the 


\section{Opinion Section}

reviews of the presence of a negative or positive relationship between them

A great number of variables are involved in learning, teaching and research activities that must be included in empirical research studies: areas (disciplines, empirical or social sciences, departments), levels (individual, departmental and institutional), institution or actor (type, class size, department size, level of study, sex, etc.), parameters (inputs, outputs, skill or outcomes) and there are other tangible factors as resource size or intangible as reputation or institutional culture, that condition the results and their meaning in comparative studies.

Unfortunately, the heterogeneous scenarios that the combination of these variables provides have been since now a great obstacle to achieve significant conclusions. As a synthesis of the present background, we can highlight some evidences from empirical research:

- Weak relationship: The evidence gathered by Qamar (2004) in several reviews of empirical research on the relationship between teaching and research in higher education (Faia: 1976, Feldman: 1987, Allen: 1996, Hattie \& Marsh: 1996, Braxton: 1996, etc.) "suggests that research and quality teaching are not contradictory roles. However, we cannot conclude from the information at hand that the link is strongly positive (...)".

- Difficult generalization. "There is a positive influence of research on teaching, and in other cases not; that students both appreciated and are sometimes irritated by staff engaging in research; that "some of the most inspiring teachers are able researchers, but not all; that some prominent researchers are good teachers, but not all" (Rowland, 2000).

- Contract factor (Actor and organization): teacher/research contract explain the effect of time spent on teaching on research. Vidal i Quintanilla (2000) show that "some aspects involved in teaching activities hinder good research. For instance, having to teach several different courses, huge groups of students, having many hours of teaching and also having an unfavourable teaching schedule, reduces the possibilities for research".

- Disruption behaviours at heterogeneous scenarios: The evidence indicates the relationship between teaching and research may be more or less modestly positive depending to stage of academic career: "it is likely to be stronger at postgraduate than undergraduate levels" Qamar (2004). Drennan (1999) discovers that the match between Research Assessment Exercise (RAE) and Teaching Quality Assessment (TQA) indices is strong for science subjects and weak for social sciences. "One of the biggest consequent problems is averaging scores across all departments of an institution, as Drennan (1999) and Drennan \& Beck (2001) do. (...) An institution could have high TQA scores for some departments but low RAE scores and vice versa" Qamar (2004).

- The lack of significant information about quality: the subjectivity inherent tendentious valuation is included in a great number of assessment references for studies, reports or rankings. For instance: in the peer review process of the RAE and in assessors' evaluations in the TQA; for defining the international reputation in rankings like Shanghai Jiao Tong University or World University Ranking of the British Times Higher Education; in the studies based in faculty and administration perceptions of Neumann (1993) Rowland (1996) Smeby (1998) Leslie et al. (1998); or in the student perceptions studies on the effects of lecturer research on learning of Neumann (1994) Jenkins et al. (1998) Lindsay et al. (2002)

- Process Time factor. a problem observed among some of the studies as Faia (1976), Noser et al. (1996), Linsky \& Strauss (1975) is the calculation of the link between research and teaching measures that cover different time frames. The analysis of the sequence that goes from L$\mathrm{T}$ to $\mathrm{R}$ must include the lifetime measure output factor.

- $\quad$ The multidimensional and complex object of the analysis could point out the preference in use of meta-analysis (the statistical integration of separate studies applied by Feldman: 1987, Allen: 1996, Hattie \& Marsh: 1996). "A study by Ellis (2001) finds a compelling match between English departments which scored highly on the RAE and those who do well on the TQA. Examining Scottish universities Drennan (1999) calculates that over $70 \%$ of the variation in means TQA scores can be explained by RAE scores" Qamar (2004). 


\section{Opinion Section}

- Critical analytical problems. The conclusions from empirical evidence studies are conditioned by critical problems inherent in using the technique to gauge the relationship and the process to measure the linkage between research and teaching. In this sense, correlation studies like Linsky \& Strauss (1975), Faia (1976), Centra (1983) Kremer (1990 \& 1991) Hattie \& Marsh's (1996) Noser et al (1996). But, "though it is a measure of linear association between two variables correlation does not imply any cause and effect relationship. Causal relations cannot be proved based on correlation coefficients" Qamar (2004).

- Size range sequence. Different results could be obtained depending on the analyzed range of the sequence (L-T-R or just T-R), the phase of the sequence (L-T or T-R); the order of sequence (R-T or TL). There is a singular link between research, teaching and learning excellence. "Evidence suggests that students in subject areas with the highest Research Assessment scores are more positive about their learning experience than were students in subject areas with lower scores". (Surridge, P., 2008) The research interferences observed in the study of Vidal i Quintanilla (2000) come from entrepreneurship: "Research collaboration with external institutions usually requires travelling and this affects teaching activities, and the most specialised research affects the most general and basic courses negatively. The setting-up of new programs increases the time required for teaching and in consequence decreases research activity.

In the debate about the correlation between learning and teaching quality, another one with social and economic repercussions is involved. "The effects of teaching quality on wage growth are unclear and we are unable to conclude whether quality effects result in temporary or permanent increases in earnings". However, "Does it pay to attend a prestigious university? (Chevalier, 2003)" Some studies have analyzed the social impact of learning: "Data released by the Higher Education Statistics Agency (HESA) shows that in 2006/07 on average $95.2 \%$ of first degree students from Russell Group universities had entered employment or further study within a year of graduating. This is $3.3 \%$ higher than the rest of the sector (not including Russell Group institutions) and a $0.4 \%$ increase on the Russell Group's figures for 2005/06". "Nearly $80 \%$ of staff in leading grade departments are employed in Russell Group Universities" (Russell Group, 2008)

\section{Entrepreneurship \& education systems. Initiatives to education system reform: Europe and EUA}

In Europe, the overarching aim of the Bologna Process (understood as its original Sorbonne declaration and the joint decisions made at various follow-up conferences held in Bologna [1999], Prague [2001], Berlin [2003], Bergen [2005], London [2007]) is to create a European Higher Education Area (EHEA) based on international cooperation and academic exchange, facilitating mobility of students, graduates and higher education staff and supporting their personal development; offer broad access to high-quality higher education, based on democratic principles and academic freedom. (BP, 2009)

The main changes proposed in the Bologna process, including legislative reforms and changes in the institutional structure (since 2007), increasing the autonomy and accountability of higher education institutions, diversification of HEIs, elimination of social and other barriers in access to tertiary education and possible transformation of existing tertiary professional education, which is governed by legislation on secondary education, into tertiary sector institutions (professionally oriented study programmes), emphasis on cooperation with employers, strengthening the responsibility of institutions and students for the quality of instruction, highlighting the role of lifelong learning, enhancing the quality of university research and, last but not least, a larger flow of financial resources into the tertiary sector" (BPTNR, 2009) .

"The overall aim is to improve the efficiency and effectiveness of higher education in Europe. The Bologna process spells out a number of "action lines" in which learning outcomes should play an important role (Adam, 2004, 2006). The main consequences of the Bologna process are:

"Qualification frameworks play a key role in developing the European Higher Education Area" (QF EHEA, 2009) as "important instruments in achieving 


\section{Opinion Section}

comparability and transparency. Qualification frameworks describe the qualifications of an education system and how they interlink. National qualification frameworks encompass all education qualifications - or all higher education qualifications in an education system. They describe what learners may be expected to know, understand and be able to do on the basis of a given qualification (learning outcomes) as well as how learners can move from one qualification to another within a system. Qualification frameworks thus focus on outcomes as much as or more than procedures, and various learning paths - including lifelong learning". (Gallavara et al., 2008). "Given that one of the main features of the Bologna process is the need to improve the traditional ways of describing qualifications and qualification structures, all modules and programs in third level institutions throughout the European Higher Education Area should be (re)written in terms of learning outcomes" Kennedy et al. (2006).

- Accreditation systems of programs: "One of the purposes of the Bologna process is to encourage European cooperation in quality assurance of higher education with a view to developing comparable criteria and methodologies" (Gallavara et al., 2008).

In EUA, the Forum for the future of Higher Education's Annual Symposium focused on assessment and accountability in higher education (Cambridge, 2007) following the Department of Education's Commission Report (2006) focuses on access, affordability, quality and accountability, came to the following conclusions related to $\mathrm{HE}$ assessment:

1) "Traditionally, institutional quality has been measured by inputs, largely in terms of financial resources and the academic qualifications of students prior to their enrolment", but "improved accountability is vital to ensuring the success" "of academic programs and institutions to serve the changing educational needs of a knowledge economy". In order to increase the quality in Higher Education, their managers "must become more transparent about cost, price, and student success outcomes and explicit in its analysis of outputs".
2) Providing timely and meaningful feedback loops on performance, efficiency and potential both to students, to teachers, to researchers, to innovation managers and to administrators at higher levels is a question of great importance on to transforming universities into $K T$ and entrepreneurial organizations capable of using their experience to improve.

3) The concept of entrepreneurship applied to first mission activities means $a$ structured set of scaffold assessment to identify and assess student and teacher progress and potential into use their knowledge, and also to promote their analytical, practical and creative skills and attitudes, to become society's leaders.

$\&$. The specific goals of the Bologna Process also include the promoting of research in higher education and placing more attention on life-long learning as a basis for a competitive economy. Following the spirit of Bologna, International and national institutions have developed systems of quality learning, quality teaching and quality research. The Bologna Process has brought about actions to developing assessment and accreditation systems.

\section{Learning \& teaching outcomes: assessment $O F$ and FOR learning and teaching: qualifications frameworks and portfolios}

The specific goals of the Bologna Process include promoting the student centred model, increasing the autonomy and accountability of universities, strengthening the responsibility of institutions for the quality of teaching, highlighting the excellence of learning, enhancing the quality of research and the transference of knowledge, as a basis for a competitive economy.

From a teacher centred to a student centred model: Stephen Adam, University of Westminster; following the Bologna Process spirit, the use of learning outcomes is intimately linked to the adoption of student-centred learning. Learning outcomes are an integral part of an output-focused approach to teaching, learning and assessment. The role of the teacher moves towards being a facilitator/manager of the learning process. Learning outcomes relate to external reference points (qualification descriptors, levels, level descriptors, subject benchmark statements) that constitute 'new style' qualification frameworks. 


\section{Opinion Section}

(Adam, 2004; 2006) This alternative model focuses on what the students are expected to be able to do at the end of the module or program.

Hence, this approach is commonly referred to as an outcome-based approach. Statements called intended learning outcomes, commonly shortened to learning outcomes, are used to express what is expected that students should be able to do at the end of the learning period" Kennedy et al. (2006).

In this context, portfolios represent "the beginning of a period of considerable change which will impact on the organisation of education and training systems, the forms of support for learning within society, the organisation of educational institutions and the development, organisation and delivery of curricula and programmes" (Attwell, G., 2007).

But: What are the learning and teaching dimensions that parameters portfolios must show in order to assure the quality of knowledge transference and the acquisition of analytical, practical and creative skills and attitudes?

Following the objectives of the Bologna Process, in the last few years, three trends have been promoted related to criteria, methodology and tools regarding assessment on higher education where portfolios have got a critical role:

- Assessment of learning and teaching. International and national institutions have developed indicator systems and agencies of quality learning, teaching and also research and transfer. Encouraging European cooperation in quality assurance of higher education has produced a great development of comparable criteria and methodologies" (Gallavara et al., 2008) involved in assessment and accreditation systems. Internal selfevaluation and external review, conducted openly by independent specialists with international expertise are vital for enhancing quality (Unesco, 1998).

- Assessment FOR learning and teaching. The overall aim of the Bologna process is to improve systematically the efficiency and effectiveness of higher education in Europe. The development of portfolios has been a "response to different pressures on the education and training systems: the implementation of e-Portfolios impacts on the organisation and pedagogic approaches to teaching and learning". (Attwell, G., 2007)
Portfolios are a purposeful collection of work that illustrates efforts, progress, and achievements that provide a straightforward means for students to collect evidence of professional or generic graduate skills, and proprietary certification (Cooper, 1999; Cooper \& Love, 2000, 2001, 2002).

- Assessment-FOR applied to assessment-OF. In the university context, the use of portfolios has been developed "as a tool for documenting personal and institutional achievements" (Jokinen et al., 2009) setting consequently as a strategic function in the extended accountability of universities realizing the student centred model of the Bologna process. Barret and Carney (2005) have been discussing about the conflict between constructivist (assessment FOR) and positivist paradigm (assessment OF). Nevertheless, "portfolios can serve both individual and institutional purposes" having two roles, personal, as a tool of self-development, or sample, as an extended curriculum vitae (Jokinen et al., 2009).

The Bologna process spells out a number of "action lines" in which learning outcomes should play an important role. (Adam, 2004, 2006) One of the logical consequences is that, by 2010 , all programs and significant constituent elements of programs in third level institutions throughout the European Higher Education Area should be based on the concept of learning outcomes, and that curriculum should be redesigned to reflect this" (Kennedy et al. (2006).

Learning outcomes are statements of what a learner is expected to know, understand and/or be able to demonstrate after completion of a process of learning. (Kennedy et al., 2006) The outcomes cover both cognitive (describe, explain, analyse etc.) and practical skills (work with others, present, write etc.). (ADC-LTSN, 2009) "Individuals and employers need to start measuring the outcomes, not just the outputs of training and learning - not 'What did I learn?' or 'What accreditation have I gained?' but 'How have I improved the way I work?" (Simmonds, 2004) "The use of learning outcomes is intimately linked to the adoption of student-centred learning. Learning outcomes are an integral part of output-focused approach to teaching, learning and assessment. The role of the teacher moves towards being a facilitator/manager of the learning process. Learning outcomes relate to external reference points (qualifications descriptors, levels, level descriptors, subject 


\section{Opinion Section}

benchmark statements) that constitute 'new style' qualification frameworks (Adam, 2004; 2006).

Qualifications frameworks also play a key role in developing the European Higher Education Area as "important instruments in achieving comparability and transparency". A qualification framework describes the qualifications of an education system and how they interlink" (Gallavara et al., 2008). "It shows what a learner knows, understands and is able to do on the basis of a given qualification that is, it shows the expected learning outcomes for a given qualification. It also shows how the various qualifications in the education or higher education system interact, that is how learners can move between qualifications. Qualifications frameworks therefore focus on outcomes more than on procedures, and several learning paths - including those of lifelong learning - may lead to a given qualification" (QF_EHEA, 2009).

\section{Form, categories of learning and teaching procedures and moments of assessment: parameters of learning and teaching portfolios}

The portfolios are now becoming essential tools for personal development planning (PDP), managing continuous professional development (CPD), gaining accreditation for prior learning (APL) and career management. "It is possible to distinguish between three broad approaches: the use of ePortfolios as an assessment tool, the use of ePortfolios as a tool for professional or career development planning (CDP), and a wider understanding of e-Portfolios as a tool for active learning". (Attwell, G., 2007) "Competency-based university education, in which lifelong learning and flexible learning are key elements, demands a renewed vision on assessment. Within this vision, assessment of Prior Learning (APL), in which learners have to show their prior learning in order for their goals to be recognised, becomes an important element" (Joosten-Ten Brinke et al. 2009).
Learning involves "the acquisition of competencies, understanding, knowledge, or skills, anytime and anywhere" (Livingstone, 2001) and "goes far beyond this formal learning. Non-formal and informal learning are two other important categories of learning that deserve more attention within the formal education system" (Joosten-Ten Brinke et al. 2009, Colardyn and Bjornavold, 2004). "Non-formal learning is not legally or socially recorded" and there isn't any certification involved, while informal learning comes from life experiences (Joosten-Ten Brinke, 2009). "It should not matter how something is learned exclusively, but it matters what is learned in relation to further personal development (Spencer et al., 20001; Joosten-Ten Brinke et al. 2009)

\section{Conclusions}

The quality in higher education is a multidimensional concept, which should embrace all its possibilities as an object, by means of a correlated analysis where portfolios could be used to convey and provide online, timely and meaningful information:

- for learning and teaching about knowledge, skills, attitude and competences,

- implemented on activity related to contents, works, practices or experience,

- on categories of formal, non-formal and in-formal processes,

- of learning, teaching and academic management,

- by means of the evidence of inputs, outputs, outcomes, and knowledge transfer processes,

- to assessment of different actors and levels such as national, institution, department, teacher, learner,

- in term of performance, efficiency and potential,

- at every moment, prior, during or Postprocess of learning-teaching. 
Opinion Section

Table 1: Analytical parameters of learning and teaching

\begin{tabular}{|l|l|l|l|l|l|l|l|}
\hline Objective & Activity & Categories & Process & Element & Level & Analysis & Moment \\
\hline & & & & & & & \\
\hline Knowledge & Content & Formal & Learning & Input & National & Performance & Prior \\
\hline Skills & Work & No-formal & Teaching & Output & Institution & Efficiency & During \\
\hline Attitude & Practices & In-formal & Management & Outcome & Department & Potential & Post \\
\hline Competences & Experience & & & Process & Teacher & & \\
\hline & & & & & Learner & & \\
\hline
\end{tabular}

Table 2: Analytical parameters of learning and teaching

\section{References}

Adam, S. (2004). Using Learning Outcomes: A consideration of the nature, role, application and implications for European education of employing learning outcomes at the local, national and international levels. Report on United Kingdom. Bologna Seminar, July 2004, Herriot-Watt University.

Adam, S. (2006). An introduction to learning outcomes, in EUA Bologna Handbook, Froment E., Kohler J, Purser L, Wilson L (Eds), article B.2.3-1. Berlin, Raabe.

Allan, J. (1996). Learning outcomes in higher education, Studies in Higher Education, 21 (10) p. $93-108$.

AUTM, The Association of University Technology Managers. Available at: http://www.autm.net/AM/Template.cfm?Sectio $\underline{\mathrm{n}=\text { FAQs\&Template }=/ C M / H T M L D i s p l a y . c f m \&}$ ContentID $=2186$

Bercovitz, J., Feldman, M., Feller, I., \& Burton, R. (2001). "Organizational structure as determinants of academic patent and licensing behavior: An exploratory study of Duke, Johns Hopkins, and Pennsylvania State Universities". Journal of Technology Transfer, 26, 21-35.

BPTNR (2009). Bologna Process Template for National Reports: 2007-2009. Available at: http://www.bologna.msmt.cz/files/nationalreport-09-cr.pdf

Brandenburg, U.; Carr, D.; Donauer, S.; Berthold, Ch. (2008). Analysing the future Market Target Countries for German HEIs. Working paper, no. 107, May. Available at: http://www.che.de/downloads/Analysing the F
uture_Market_Target_Countries_for_German_ HEIs_AP107.pdf

Bricall, J. M. (2000). Universidad 2mil. Madrid; CRUE.

Carlsson, B. (1994). "Technological Systems and Economic Performance". In: M. Dogson and R.Rothwell (Ed.): The Handbook of Industrial Innovation. Cheltenham: Edward Elgar.

Chalmers, D. (2007). A review of Australian and international quality systems and indicators of learning and teaching. August, 2007. V.1.2. Available

http://www.catl.uwa.edu.au/__data/page/14682 7/T\&L_Quality_Systems_and_Indicators.pdf

Chalmers, D. (2008). Indicators of University Teaching and Learning Quality. Available at: http://www.catl.uwa.edu.au/__data/page/14682 7/Indicators of University Teaching_and_Lear ning Quality.doc

Chevalier, A.; Conlon, G. (2003). "Does it pay to attend a prestigious university?" Arnaud Chevalier and Gavan Conlon, March 2003, Centre for the Economics of Education, LSE.

CHE (2009). Centre for Higher Education Development. Available at: http://www.checoncept.de/cms/?getObject=302\&getLang=en

Clark, B. (1998). Creating Entrepreneurial Universities: Organisational Pathways of Transformation. Oxford, New York, Tokyo: International Association of Universities and Elsevier Science.

Commission of the European communities (2006). Communication from the Commission Delivering on the modernisation agenda for universities: education, research and innovation. Brussels; Commission of the European Communities. 


\section{Opinion Section}

Etzkowitz, H.; Leydesdorff, L. (1997). University and the Global Knowledge Economy. A Triple Helix of University- Industry- Government Relations. London; Pinter Publishers.

Etzkowitz, H. Webster, A. Gerhardt, C., Terra, B. (2000). "The future of the University and the university of the future: evolution of ivory tower to entrepreneurial paradigm", Research Policy, 29 (2): 313-330.

DESTAG, Department of Education, Science and Training or the Australian Government (2006). Knowledge transfer and Australian Universities and publicly funded research agencies. A report to the Department of Education, Science and Training.

European Commission (2003a). Third European Report on Science \& Technology Indicators. Brussels; European Commission.

European Commission. (2003b). Thematic Trend Report: Industry-Science Relations. Brussels: European Commission.

Gallavara, G.; Hreinsson, E.; Kajaste, M.; Lindesjöö, E.; Sølvhjelm, C.; Sørskår, A.K.; M. Sedigh Zadeh, M. (2008). Learning outcomes: Common framework - different approaches to evaluation learning outcomes in the Nordic countries. Joint Nordic project 2007-2008, by the Nordic Quality Assurance Network for Higher Education (NOQA). Available at: http://www.enqa.eu/files/NOQA\%20report_occ asional\%20papers\%2015.pdf

Gosling, D. and Moon, J. (2001). How to use Learning Outcomes and Assessment Criteria. London: SEEC Office.

Gulbrandsen, M.; Slipersaeter, S. (2007). The third mission and the entrepreneurial university model. At: Bonaccorsi, A.; Daraio, C. (eds.) Universities and Strategic Knowledge Creation. USA; Edward Elgar.

Higher Education Statistics Agency (HESA). Available at: http://www.hesa.ac.uk/

Howard Partners (2003). Evaluation of the Cooperative Research Centres Programme. Report of a study commissioned by the Department of Education, Science and Training.

Howard Partners (2005a). The emerging business of knowledge transfer: Creating value from intellectual products and services. Report of a study commissioned by the Department of Education, Science and Training.

Howard Partners (2005b). Knowledge exchange networks in Australia's innovation system: overview and strategic analysis. Report of a Study Commissioned by the Department of Education, Science and Training.

Howells, J. (2006). "Intermediation and the role of intermediaries in innovation". Research Policy, 35, 175-728.

Kennedy, D.; Hyland, A.; Ryan, N. (2006). Writing and Using Learning Outcomes: a Practical
Guide.

Available

at:

http://www.bologna.msmt.cz/files/learningoutcomes.pdf

Mager, R. F. (1984). Preparing instructional objectives . 2nd ed., Belmont, California: Pitman Learning.

Molas-Gallart, J., Salter, A., Patel, P., Scott, A., Duran, X. (2002). Measuring third stream activities. Brighton: SPRU.

Molas-Gallart, J.; Castro-Martínez, E. (2006). "Ambiguity and conflict in the development of «Third Mission» indicators". At The 9th International Conference on Science and Technology Indicators; Lovaina.

Molas-Gallart, J.; Castro-Martinez, E.; Fernandezde-Lucio, I. (2008). "Interface structures: knowledge transfer practice in changing environments". Ingenio Working Paper Series no. 2008/4.

OECD-AHELO (2008a). OECD Feasibility Study for the International Assessment of Higher Education Learning Outcomes (AHELO). Available at: www.oecd.org/edu/ahelo

OECD-AHELO (2008b). Roadmap for the OECD assessment of higher education learning outcomes (AHELO) feasibility study. Available at:

http://www.oecd.org/dataoecd/50/50/41061421. pdf

OECD (2009). Assessment of learning outcomes in higher education: a comparative review of selected practices. Available at:http://www.oecd.org/document/51/0,3343,en 2649_35961291_42295603_1_1_1_1,00.html

O'Shea, R., Roche, F., Allen, T., \& Chevalier, A. (2005). "Entrepreneurial orientation, technology transfer and spinoff performance of US Universities". Research Policy, 34(7), 9941009.

Polt, W., C. Rammer, H. Gassler, A. Schibany, and D. Schartinger. (2001). "Benchmarking industry-science relations: the role of framework conditions". Science and Public Policy, 28 (4):247-258.

QF_EHEA (2009). Qualifications Frameworks in the EHEA. Bologna Process official web site. European Higher Education Area (EHEA) Available at: http://www.ond.vlaanderen.be/hogeronderwijs/ bologna/qf/qf.asp

UNESCO (1998). "The World Declaration on higher education for the twenty-first century: vision and action adopted by the World Conference on Higher Education. Higher Education in the Twenty-First Century: Vision and Action by 9 October 1998. Available at: http://www.unesco.org/education/educprog/wch e/declaration eng.htm\#world\%20declaration 